\title{
La construcción poética del trabajador en el disco Construção, de Chico Buarque de Hollanda*
}

\author{
Cristian Galarce, U. de Valparaíso \\ cristiangalarcelopez@gmail.com
}

\author{
Lucía Di Salvo, U. de Valparaíso ${ }^{1}$ \\ luciadisalvo@gmail.com
}

\begin{abstract}
Resumen
Este artículo analiza la obra del escritor y compositor carioca Chico Buarque, buscando mostrar cómo desarrolla una construcción poética de la subjetividad del trabajador de clase popular brasileña, a inicios de la década del setenta. La unidad de análisis delimitada es el LP Construção, de 1971. En él, se presentan numerosas estrategias musicales y literarias que Buarque usa para re-crear poéticamente la vida, los pensamientos y el sentir del sujeto trabajador en un contexto de represión, prohibiciones y censura ejercidas contra el pueblo por la dictadura militar en Brasil.
\end{abstract}

Palabras clave

MPB, Chico Buarque, trabajador, bossa nova, poética.

\section{Poetic Construction of the Worker in Chico Buarque de Hollanda's LP Construção}

\begin{abstract}
This article analyzes the work of Carioca writer and composer Chico Buarque, aiming to demonstrate how he develops a poetic construction of Brazilian working-class subjectivity during the early 1970s. The analysis focuses on the LP Construção (1971), displaying the numerous musical and literary strategies that are present. Buarque uses these strategies to poetically recreate the life, thoughts, and feelings of workers in the context of repression, prohibitions, and censorship imposed by the Brazilian military dictatorship.
\end{abstract}

Keywords

MPB, Chico Buarque, worker, bossa nova, poetics.

\footnotetext{
* Recibido: 26 de febrero de 2016 / Aceptado: 9 de junio de 2016.

${ }^{1}$ Tesista del Doctorado en Estudios Interdisciplinarios sobre Pensamiento, Cultura y Sociedad de la Universidad de Valparaíso en el proyecto Fondecyt Iniciación 11140839. IR: Patricio Herrera.
} 


\section{Introducción}

El presente artículo tiene como eje central el LP Construção (1971), de Chico Buarque de Hollanda. Particularmente, abordamos las operaciones poéticas que el autor utiliza a lo largo del disco, estudiándolas en el marco de lo que consideramos un ejercicio de construcción poética del trabajador. Un supuesto de nuestro trabajo es la idea de que el personaje que muere en la canción "Construção" trasciende a la canción misma y atraviesa el disco completo, de manera que Buarque re-crea (en concordancia con la etimología de poiesis) la vida cotidiana de un trabajador de la denominada clase popular brasileña, enfocándola desde múltiples ángulos, a través de diversos hablantes y mediante variadas operaciones poéticas. Y lo hace a partir del género canción, en el contexto del movimiento llamado Música Popular Brasileira (en adelante, MPB).

En este artículo proponemos un análisis que atiende al resultado de la conjunción entre música y poesía en el género canción. Esto, sin desestimar las incidencias particulares que cada una de estas artes tiene, por separado, en el total de la obra. Nuestro interés central es, entonces, el sentido que emerge de la conjunción como tal, partiendo de la premisa de que el concepto de construcción poética es irreductible al de poesía. En este punto es importante destacar que la poética admite al menos tres definiciones (Marchesse \& Fordarellas, 1989): 1. Una teoría interna de la literatura que, como tal, se propone explicar todo el arte; 2 . Un conjunto de reglas prácticas cuyo empleo se hace obligatorio para pertenecer a cierto grupo; y 3. Una elección hecha por un autor entre todas las posibilidades. Nos desplazamos a lo largo de las tres definiciones, pero la primera es la que nos sirve de eje, puesto que elaboramos en este texto la idea de que la poética puede ser una herramienta conceptual para explicar el arte. Esta premisa nos permite centrarnos en nuestra idea general acerca de la construcción que está implícita en el disco en cuestión. En cuanto a la segunda definición, la ampliamos: la ausencia o transgresión de las reglas también puede ser una regla dentro de una poética. Porque el término "poética", en tanto adjetivo derivado de "poesía", no puede ignorar en ningún caso su naturaleza libre, ni tampoco -ya desde su etimologíadesligarse de su cualidad performativa. Finalmente, en cuanto a la tercera definición, nos centramos en las estrategias poéticas que operan en la escritura de Buarque, situándolas histórica y políticamente.

A partir de estas ideas, en primer lugar, realizamos un breve recorrido en torno a la Nueva Canción Latinoamericana, enfocando la MPB en tanto voz de protesta (Dias Cavalcanti, 2012; Velasco, 2007). En segundo lugar, indagamos en la producción de Chico Buarque anterior a 1971, buscando mostrar cómo el contexto es de suma relevancia para comprender su producción artística, y de qué modo incide la censura en la creación de sus canciones (Baldam, 2015; Gomes, 2009; 
Kogawa, 2004). En tercer lugar, abordamos la confluencia entre música y literatura en la música popular (Werney, 2009; Carmo, 2007), poniendo atención a la música que subyace a toda palabra poética (Salas, 2011). Finalmente, damos ejemplos de estrategias poéticas a través de un análisis literario de las canciones (se visualizan la presencia de estrategias de ficcionalización o la utilización de recursos poéticos, por ejemplo). Este recorrido da cuenta de la existencia de una unidad a lo largo del disco: la construcción poética de un trabajador que nace, vive y muere en Construção.

\section{La MPB en el contexto de la Nueva Canción Latinoamericana}

La tradición de la canción popular urbana, como modo consolidado de comunicación artística en nuestras sociedades modernas y expresión decidida del imaginario popular, fue uno de los elementos fundacionales en el origen del surgimiento de la Nueva Canción Latinoamericana. Tanto es así que, en la década de 1960 emergieron cambios profundos en la manera de pensar el mundo, principalmente en la población joven, que se mostraba ansiosa por cambios, reformas y revoluciones. En el ámbito de la música popular, los años sesenta "estuvieron marcados por la crítica a las instituciones, al modo de producción capitalista y, sobre todo, estuvieron signados por la reacción colectiva frente a un sistema sociopolítico considerado represivo" (Velasco, 2007:142). En Latinoamérica, la nueva canción se manifestaba contra el imperialismo, las injusticias económicas y las diferencias sociales generadas por el sistema, y a favor de los pueblos originarios y de los derechos humanos y ciudadanos. Asimismo, mostraba una clara disidencia en contra de las dictaduras que en la época proliferaban en el Cono Sur. En consecuencia, la canción se convirtió en un canal de comunicación posible en contextos hostiles a causa de la censura. Como resultado, la Nueva Canción Latinoamericana se transformó en símbolo reconocido de una conciencia compartida de lo que era y debía ser Latinoamérica. En este contexto y teniendo en cuenta que existen estrechos lazos en el trabajo de diversos autores e intérpretes a lo largo del continente latinoamericano, surgen paralelamente expresiones tales como el nuevo cancionero argentino, con Atahualpa Yupanqui, Facundo Cabral y Mercedes Sosa; la nueva canción chilena, con Violeta Parra, Víctor Jara, Quilapayún e Inti-illimani; en Uruguay, Daniel Viglietti y Alfredo Zitarrosa aparecen como exponentes del nuevo canto; y en la nueva trova cubana reconocemos los nombres de Carlos Puebla, Silvio Rodríguez, Vicente Feliú y Pablo Milanés. Todos músicos que "se plantean problemas fundamentales asociados a la composición musical y al necesario compromiso político de los músicos con la izquierda latinoamericana, en esencia antiimperialista y revolucionaria" (146).

En Brasil, el bossa nova ("nuevo estilo") fue uno de los principales movimientos que participaron de esta renovación de época que, junto al Tropicalismo y la MPB, 
contaba con algunos de los compositores más renombrados del país: Antônio Carlos Jobim, João Gilberto, Caetano Veloso, Milton Nascimento, Toquinho, Edu Lobo y Chico Buarque, entre otros. El bossa nova, originado a principios de los años 1950, entrelaza la tradición de la samba y la música popular con la influencia del jazz, incluyendo -en algunos casos- rasgos del impresionismo francés en el plano musical armónico². Más allá de estas múltiples influencias, el bossa nova se mantuvo permanentemente vinculado, en lo profundo, a la historia musical de Brasil y su diversidad de texturas, armonías, timbres y ritmos. A la complejización melódica, armónica y tímbrica -y otras búsquedas en el campo de la composición musical- se suma un notable interés por las temáticas modernas, en el plano de la palabra. Así, paulatinamente se incorporan autores provenientes del mundo de la literatura, como Mário de Andrade y Vinícius de Moraes, escritores que al poco tiempo se tornan ampliamente reconocidos como parte del cancionero MPB.

Para Luciano Dias Cavalcanti (2012), después de un período inicial de bossa nova que tendía a tratar más bien temáticas livianas -los dramas pasionales, el mar, el sol, el amor, la luna-y que culmina alrededor de 1962, se produce una irrupción de temas que acompañan la evolución de los problemas políticos de Brasil, ligando explícitamente la creación artística con el desarrollo político y social. Emerge entonces la MPB, surgida a partir del desarrollo histórico del bossa nova, como un movimiento que buscaba hablar de la realidad cotidiana y del presente, de lo contingente, en el contexto de las demandas que presentaba la efervescencia política y cultural de la época. La MPB de las décadas de 1960 y 1970 muestra un carácter contingente y circunstancial y, por lo tanto, asume muchas veces "una dimensión casi periodística, pasando a reflejar casi directamente los acontecimientos del día a día. [...] se vuelve un vehículo de comunicación que dice lo que los canales competentes de comunicación no podían decir" (2012: 6). En efecto, la MPB canalizó la necesidad social de formación de colectivo, de participación de la juventud y de debate público a través de festivales, conciertos y discos.

\section{Censura, transgresión y poética}

Si bien es recurrente la idea de que la literatura no pretende explicar la historia y que la historia jamás podrá explicar la literatura, no se puede evitar reconocer que la poesía, en tanto producto social, es también un producto histórico (Paz, 1994). Por tanto, es imposible ignorar la relación de la poesía con la sociedad, ni

\footnotetext{
${ }^{2}$ Cuestión observable, por ejemplo en "Sabiá", de Buarque y Tom Jobim. Este último, particularmente, se muestra influenciado de manera importante por Claude Debussy, Maurice Ravel, Fréderick Chopin y Heitor Villalobos, entre otros, cuyas obras conoció a través de maestros de composición como Hans Joachim Koellreutter.
} 
tampoco la relación de la vida con la obra de un poeta. Por otro lado, según Octavio Paz, en el mundo moderno -signado por un sistema de prohibiciones y autorizaciones- la poesía (género no moderno) se manifiesta propiamente como rebelión, porque su naturaleza es indiferente a los dogmas de la modernidad. La poesía, para este autor, implica una transgresión a la racionalidad y a la moralidad de la sociedad burguesa. De ahí que esta manifestación artística surja naturalmente como mecanismo de expresión urgente ante un sistema de prohibiciones que es, en el caso que nos convoca, el discurso hegemónico sostenido por la clase dominante en el contexto particular de la dictadura militar brasileña (1964-1989).

Este sistema de prohibiciones que implica la imposición militar del año 1964 tiene su correlato civil en la imposición de un discurso de poder sostenido y apoyado por los principales periódicos y revistas, por la clase política, el empresariado, la iglesia católica y los propietarios rurales. Ese poder estriba en las palabras, pues, tal como afirma Pierre Bourdieu, el lenguaje, además de tener la función de comunicar, ejerce "un poder típicamente mágico: persuadir, influir" (cit. Éribon, 1982). Desde este punto de vista, podemos afirmar que las clases populares se convirtieron en objeto de opresión permanente mediante el poder simbólico de las palabras, mientras que, al mismo tiempo, se llevaba a cabo una violenta política de persecución y represión de los disidentes. Tanto es así que, en el contexto de opresión militar, el ejercicio de poder y vigilancia de la censura estaba sustentada en la publicación de un texto, un dispositivo legal: el Acto Institucional n. 5, del 13 de diciembre de 1968, "implementado porque Brasil estaba a punto de convertirse en un país comunista", y fortalecido por la Ley de Seguridad Nacional, de 1969, que decretaba exilio y pena de muerte en casos de "guerra psicológica adversa, o revolucionaria, o subversiva" (Carvalho et al., 2015). Esto permitió a los censores gubernamentales establecer un duro régimen de revisión de todo el material artístico antes de ser publicado, de modo que la censura afectó en múltiples ocasiones la obra de importantes artistas de la época, como Caetano Veloso, Gilberto Gil, Milton Nascimento, Chico Buarque, entre muchos otros. Este último autor, con un alto número de canciones censuradas, fue detenido en diciembre de 1968 y luego liberado con prohibición de dejar Rio de Janeiro. En enero del año siguiente, solicitó un permiso para viajar a Cannes y al lanzamiento de un disco en Roma, Italia. Es en este último país donde decidió quedarse con su familia hasta 1970, al considerar que no se daban las condiciones necesarias de seguridad para volver a Brasil (Oliveira, 2005).

Veremos en adelante cómo -al mismo tiempo que el proyecto hegemónico de la dictadura brasileña dejaba por fuera el protagonismo de la clase popular (Moraes, 2004)- los autores y compositores de la MPB buscaban recuperar y recrear las subjetividades marginales en su universo poético y musical. Tanto es así que, en Construção, los protagonistas de los poemas son, justamente, personajes de 
la denominada clase popular brasileña cuyo discurso cantado es tomado como una lucha emergente por parte de los sujetos de la clase trabajadora silenciada.

\section{Buarque en la década de 1960: "Roda Viva", "Sabiá" y "Samba de Orly".}

Como hemos señalado, Buarque es uno de los compositores cuya trayectoria se ve influenciada por la necesidad de hacer frente a la situación política de su tiempo. Esto se puede observar en su trabajo creativo previo a 1971, en el cual es visible un paulatino acercamiento a temáticas contingentes que parecieran tener un punto de llegada pleno en el disco Construção. En su trabajo, la voz de protesta se encuentra entrelazada frecuentemente con temáticas amorosas y, en muchas ocasiones, festivas o carnavalescas, pero manteniendo en lo profundo una constante atención sobre la problemática política contingente de su país, que considera aplastado por la dictadura y exprimido por problemas económicos provocados por una agenda externa que lo sofoca (Salles, 1989). A través de tres ejemplos, mostraremos cómo la especial capacidad de Buarque para tratar temas sociales y políticos en texturas polisémicas antecede y prepara las estrategias de composición del disco Construção.

\section{i. "Roda Viva"}

Un primer ejemplo importante de destacar, en el sentido señalado, es el de "Roda Viva", canción que, en 1967 -plena dictadura-, obtiene un tercer lugar en el III Festival de Música Popular Brasileira da TV Record. Esta canción presenta sin duda un discurso crítico ante la situación política del país y una visión pesimista de su tiempo. Y hace todo esto en fuerte tono melancólico, pero, paradójicamente, también en festivo ritmo de samba. Sumado a esto, el autor entreteje hábilmente -ya desde el título- la temática política propiamente tal con figuras poéticas como "la rueda de la vida", "mandar al destino", "hacer serenata" o las "vueltas del corazón", que, al mismo tiempo, hacen pensar en metáforas y analogías más bien vinculadas a las canciones populares de temática amorosa.

Mas eis que chega a roda-viva

E carrega o destino pra lá

Roda mundo, roda-gigante

Rodamoinho, roda pião

O tempo rodou num instante

Nas voltas do meu coração ${ }^{3}$
Pero he aquí que llega la rueda de la vida Y lleva al destino para allá

Rueda mundo, rueda gigante

Rueda molino, rueda peón

El tiempo rodó en un instante

En las vueltas de mi corazón ${ }^{4}$

\footnotetext{
${ }^{3}$ Salvo que se indique lo contrario, todas las letras de canciones de Chico Buarque, tanto en portugués como en español, han sido transcritas de su sitio web oficial.

${ }^{4}$ Nuestra traducción.
} 
Esta música es, a su vez, la parte central de la banda sonora de la pieza de teatro del mismo nombre, que Buarque estrena en 1968 en Río de Janeiro, siendo ésta su primera incursión como dramaturgo (Oliveira, 2006). La obra es estrenada en un momento de radicalización de la dictadura y -debido a su contenido políticoprovoca una reacción de grupos de derecha vinculados al régimen que "culminó con agresiones a los actores y la destrucción del escenario del Teatro Galpão, en São Paulo, seguidas de nuevas agresiones en Porto Alegre" (Severiano, 1997). Junto a la acción de la censura gubernamental, esto provoca la suspensión del montaje. En una carta dirigida a la Jefatura de la Censura Federal de São Paulo, el censor observa que el espectáculo teatral es "degradante y de cierto modo hasta subversivo" y que el autor, Francisco Buarque de Holanda, no respeta la formación moral del espectador, hiriendo los principios de enseñanza moral y religión. Además, "no olvida también la parte política y hace severas críticas, aunque de modo inteligente, provocando al espectador para que haga una toma de posición" (Carvalho et al., 2015).

\section{ii. "Sabiá"}

Dentro de la producción musical de Buarque previa a Construção, un segundo caso notable por lo fino de la naturaleza polisémica del mensaje es el de "Sabiá" (1968), en el que participa como autor para una música compuesta por Tom Jobim. La canción obtiene el primer lugar en la fase nacional del III Festival Internacional da Canção, en 1968, y pasa a representar a Brasil en la fase internacional del mismo festival, donde también gana. Según Irna Priore, aun cuando la audiencia prefería sin duda el tema "Pra não dizer que não falei das flores" (Caminhando), de Geraldo Vandré, "las autoridades del festival sintieron que habría sido políticamente embarazoso enviar una canción tan políticamente cargada a representar a Brasil afuera, así que 'Sabiá' fue elegida a cambio" (2014: 11). Esto explicaría por qué la canción no fue considerada por el público, en su momento, como portadora de contenido político. Al respecto, Dias Cavalcanti plantea que, "comparada con el compromiso explícito de 'Caminhando', 'Sabiá' era vista como una canción desvinculada de la realidad brasileña y como esencialmente lírica", cuestión que explica por qué muy pocos en ese momento logran advertir en ella una "canción premonitoria del exilio" (2012: 10) que estaba muy próximo a acontecer.

\footnotetext{
${ }^{5}$ Esta se convertiría con el tiempo en un importante himno de la resistencia contra la dictadura por su carácter marcado de protesta, que puede notarse en el siguiente fragmento: "Hay soldados armados, amados o no. [...] En los cuarteles les enseñan una antigua lección, de morir por la patria y vivir sin razón" Nuestra traducción.
} 
Resulta importante tener en cuenta que el texto de "Sabiá"6 -que Buarque escribe para la música de Jobim- es una relectura del poema "Canção do exílio", escrito en 1843 por Antônio Gonçalves Dias, mientras el escritor vivía su exilio en Portugal. Ambos textos expresan la nostalgia por la tierra de origen y el dolor de no poder regresar al lugar al que se pertenece. Sin embargo, Buarque, quizá buscando representar un exilio imaginado o una especie de exilio en la propia tierra, como imagen poética de ficción, plantea una doble inversión en el contenido del poema. El "yo" del poema de Gonçalves expresa una añoranza y ruega, desesperanzado, por el regreso a una tierra que narra bella, cuyas aves, bosques, palmeras, flores y amores le están privados en el lugar de exilio:

Minha terra tem palmeiras

Onde canta o sabiá.

Não permita Deus que eu morra

Sem que eu volte para lá;

Sem que desfrute os primores

Que não encontro por cá;

Sem que ainda aviste as palmeiras

Onde canta o sabiá.
Mi tierra tiene palmeras

Donde canta el sabiá

No permita Dios que muera

Sin que vuelva para allá

Sin que disfrute los primores

Que no encuentro por acá

Sin que al fin vea las palmeras

Donde canta el sabiá7.

En su relectura del poema, Buarque plantea no el ruego, sino la certeza del retorno, la seguridad: "sé que finalmente volveré". Aunque el retorno se dará a un lugar en el que ya no hay palmeras, flores, ni amores, pues allí está impuesta una noche permanente que es necesario espantar para dar paso al día:

Vou voltar

Sei que ainda vou voltar

Vou deitar à sombra

De uma palmeira

Que já não há

Colher a flor

Que já não dá

E algum amor

Talvez possa espantar

As noites que eu não queria

E anunciar o dia...

[...]

Vou voltar

Sei que ainda vou voltar

Para o meu lugar
Volveré

Sé que finalmente volveré

Me recostaré en la sombra

De una palmera

Que ya no está

Tomaré una flor

Que ya no da

Y algún amor

Tal vez pueda espantar

Las noches que no quería

Y anunciar el día...

[...]

Volveré

Sé que finalmente volveré

A mi lugar

\footnotetext{
${ }^{6}$ El sabiá (sabiá-laranjeira), cuyo nombre científico es turdus rufiventris (tordo de barriga castaña), es el ave símbolo del estado de São Paulo, considerada también -junto al ararajuba- como ave símbolo de Brasil.

${ }^{7}$ Nuestra traducción.
} 
Foi lá e é ainda lá

Que eu hei de ouvir cantar

Uma sabiá

Cantar uma sabiá
Fue allá y aún será allá

Que habré de oír cantar

Una sabiá

Cantar una sabiá8

En el poema se construye un imaginario de nostalgia por el lugar añorado, característica que se ve reforzada, en lo musical, por el plan armónico decididamente debussiano que Jobim plantea en "Sabiá". En la pieza, además de la orquestación -también de ascendencia impresionista-, se observa una tendencia a la manipulación tonal cromática, un plan armónico inestable y un constante quiebre de las expectativas tonales ${ }^{9}$ (Dias Cavalcanti, 2012; Priore, 2014). La suma de estos factores contribuye a la elaboración poética de un imaginario de nostalgia por el lugar perdido, expresado a través de un guiño a la mirada impresionista sobre la naturaleza. Este imaginario es propio de fuentes pictóricas tales como la obra de Claude Monet (Nymphéas; Impression, soleil levant; Les Champs au printemps), está presente en la poética simbolista de Paul Verlaine (Soleils couchants; Effet de nuit; L'angoisse), y, como hemos adelantado, es parte de la obra musical de Claude Debussy (La Mer; Prélude à l'Après-midi d'un faune; Clair de Lune). Resulta importante tener esto en cuenta, pues Buarque escribe su texto para una música ya existente, cuyas características particulares ofrecen el marco sobre el cual opera su relectura de "Canção do exílio", de Gonçalves.

\section{iii. "Samba de Orly"}

Un tercer caso que consideramos importante es el de "Samba de Orly", compuesta en 1970, mientras Buarque se encontraba en Italia, con ocasión del regreso de Toquinho al Brasil. El título original era "Samba del exilio", pero la censura obligó a los autores (Vinicius, Toquinho y Buarque) a cambiarlo para poder publicarlo. Como resultado del paso del texto por la auditoría de los censores, Buarque acaba editando la canción en el álbum Construção con este nuevo título y con modificaciones exigidas por la censura en dos versos, cambiando "omisión" por "duración" y "un tanto forzada" por "de esta temporada":

Pede perdão

Pela omissão (duração)

Um tanto forçada (dessa temporada)

Mas não diga nada,

Que me viu chorando

$[\ldots]$
Pide perdón

Por la omisión (duración)

Un tanto forzada (de esta temporada)

Pero no digas nada

Que estuve llorando

[...]

\footnotetext{
${ }^{8}$ Nuestra traducción.

${ }^{9}$ Estas características son claramente observables en la versión del disco Stone Flower, de Tom Jobim (1970).
} 
E se puder me manda

Uma notícia boa
Y si puedes me mandas

Una noticia buena ${ }^{10}$

Debido a estos y otros muchos ejemplos, Buarque se convirtió paulatinamente en uno de los autores más hostigados por la dictadura militar brasileña, viéndose obligado a lidiar con la censura permanentemente, así com a desarrollar estrategias compositivas y líricas que le permitieran seguir publicando su trabajo. Construção es producido por el autor en el año 1971, recién retornado de su exilio en Italia y acosado por los organismos censores -quienes en 1974 llegan incluso a prohibirle por completo grabar sus propias composiciones. A partir de esto, decide publicar el disco Sinal Fechado (1974), con canciones de otros autores -Veloso, Gil, Jobim, de Moraes, Toquinho-y donde utiliza por primera vez los seudónimos "Julinho da Adelaide" y "Leonel Paiva", para ocultar a la censura su propio trabajo como autor y compositor.

\section{Confluencias entre poesía y música}

Dado que nos abocamos al análisis de la palabra cantada, resulta relevante atender a trabajos que traten, desde diversos puntos de vista, las relaciones de confluencia entre poesía y música. En este marco, es interesante el aporte de Leonardo Martínez, quien señala que todo poema es una construcción sonora y que, como tal, forma parte del elemento fundacional de la música, es decir, el ritmo. Este último es un artificio que funciona a partir del curso de las vocales y consonantes que constituyen el poema, conformando la melodía del verso. Por tanto, el ritmo y la melodía "laten en el fluir de la palabra poética", mientras ese latido "puede, o no, ser acompasado, mensurado. No interesa" (Martínez, 2011: 83). Por otra parte, Horacio Salas plantea que todo lector de poesía es capaz de intuir la música de ciertas combinaciones de palabras y que, en las coincidencias entre música y poesía, surgen dificultades de asimilación y unidad porque se trata de dos expresiones que se centran en tocar "aspectos destinados a producir emociones, a conmocionar" (2011: 109). En la misma línea, Robert Louis Stevenson (2014) insiste en que la belleza del contenido de un poema es indivisible de su sonoridad y cadencia. No podemos dejar de recordar, por cierto, a propósito de esto, la conocida anécdota en la que Debussy le comenta a Mallarmé que le ha puesto música al poema "La siesta del Fauno", a lo que el poeta responde con una pregunta: "¿acaso no la tenía ya?".

Más específicamente, atendiendo a la confluencia entre poesía y música en el género canción, Alfredo Werney plantea que, para comprender la construcción

\footnotetext{
${ }^{10}$ Traducción de Silvia Ulrik y Roberto Echepare, 1970, en sitio web oficial de Chico Buarque (Homem, SF).
} 
de sentido de una canción, es necesario tener en cuenta lo fundamental que resulta ser la articulación entre la melodía y la prosodia. La forma en que se ordena la fusión entre melodía y palabra es de un equilibrio tenso, en el que algunas veces predomina uno de los sistemas de signos involucrados y, a veces, otro. Se trata, entonces, "de un combate entre melos y logos -combate que existe desde la Grecia antigua, cuando aún no se establecía una distinción clara entre poesía y música" (2009: 6-7). Werney retoma el trabajo de José Roberto do Carmo (2007) para tratar el tema, señalando que en una canción actúan, como fuerzas opuestas, la jerarquía melódica -de optimización musical armónica, que tiende a prevalecer en las canciones de temática pasional- y la jerarquía prosódica -de optimización rítmica, cuyos principios prevalecen o tienen mayor presencia en la canción figurativa. Para Carmo, un cantor popular es por excelencia un enunciador sincrético que "flexibiliza la oposición entre música y verbo, entre mélos y lógos". Asimismo, plantea que, a diferencia de lo que ocurre en general en la tradición musical, donde "las palabras suelen esconderse detrás de las melodías, y otras veces son las melodías las que se esconden atrás de las palabras", en la canción popular ocurre que "el canto consigue driblar ese juego de figura-fondo, trayendo al centro de la escena el cantar de la palabra y el decir de la línea melódica" (2007: $48)^{11}$. El cantor popular lograría, en este sentido, una especie de síntesis entre melodía y palabra, al descifrar el secreto del vínculo que estos universos opuestos guardan entre sí.

En relación a lo anterior, es importante tener en cuenta que, en la MPB en particular y en Nueva Canción Latinoamericana en general, se puso énfasis en la revalorización de la oralidad del texto poético como medio para exhibir las realidades de las masas. Este vuelco a la oralidad propulsó la difusión de una poesía enmarcada en un movimiento cultural emergente capaz de crear una propuesta comunicacional que unificara y borrara las líneas entre la cultura oral -medio que ensancha las vías comunicativas- y la escrita -medio signado por los prejuicios asociados al universo letrado (Antequera, 2008). Asimismo, según Dias Cavalcanti (2011), en el encuentro de la música y la poesía que propició la MPB en los años 1970 se beneficiaron ambas disciplinas, puesto que la música popular tomó de la poesía el rigor del trato con la palabra, mientras que la poesía extrajo de la música los elementos populares y los ritmos propios del pueblo.

\footnotetext{
${ }^{11}$ Resulta adecuado detenerse un momento en la mención que hace Carmo al concepto driblar (Del inglés to dribble, en español driblar, eludir, regatear, fintar (chi), gambetear (arg). propio del fútbol y otros deportes) que se refiere a engañar o burlar hábilmente al adversario. Para Marcadet, driblar implica "una estrategia de astucia" y resulta un concepto muy adecuado para plantear cómo el compositor enfrenta la problemática de la censura, planteando que Buarque utiliza el término por primera vez en sus letras en Agora falando sério, de 1969, y lo retoma posteriormente en varias entrevistas, a tal punto que éste podría "ser identificado estrechamente con su persona y su lucha contra la censura en Brasil” (2005).
} 


\section{Poética de la construcción: ficción, performatividad e identificación.}

En las composiciones de Buarque, la poesía ingresa en la rutina, en la casa y en la vida de personajes ficticios-reales. Y nos tomamos la licencia (poética) de fusionar lo ficticio con lo real porque no podemos desligarnos del supuesto de que el personaje que muere en la pieza "Construção" es el mismo personaje que vive, trabaja, besa a su mujer, come, hace dormir a su hija y se levanta de madrugada a lo largo de todo el disco. Esta unidad estructural que surge en la canción "Construção" y que da el título -no casualmente- al disco, está protagonizada por un hombre de clase media-baja que bien podría ser cualquier hombre trabajador de las clases populares de Brasil en el contexto de la dictadura.

En este punto, la díada ficción-realidad se vuelve tan o más difícil de desentrañar que el entramado música-poesía. A propósito de esto, es pertinente retomar los trabajos de Wolfgang Iser y Benjamín Harshaw: el primero afirma que no es extraño que a la literatura se le haya atribuido la etiqueta de "mentiras" y que, a partir de un análisis más profundo, se deduzca que la mentira sobrepasa a la verdad, así como la obra literaria sobrepasa el mundo real, aun cuando el acto de ficcionalizar depende siempre de un contexto (Iser, 1997: 43-44). El segundo define el término ficcionalidad como un lenguaje que ofrece proposiciones sin pretensión de valores de verdad en el mundo real (Harshaw, 1997: 126-127). En otras palabras, se debe tener en cuenta que los enunciados fictivos no necesariamente tienen un correlato con el mundo real, no habiendo ningún compromiso pactado al respecto entre narrador y lector. Sin embargo, sí existe un marco de referencia, es decir, una interrelación entre diversos referentes -acontecimientos sociales, personajes, situaciones políticas, etc.- que permiten observar con más detalle el proceso de producción de la ficcionalidad. Esto nos habilita a pensar en la ficción como una unidad estructurante que participa en la construcción poética del trabajador que nace en "Minha Historia" y muere en "Construção". Esta ficción construida en torno al personaje deja entrever las contradicciones sociales que lo sumen en la injusticia, que lo hacen pelear duramente por su subsistencia, que lo incitan en todo momento a empoderar una voz de protesta y que no logran impedir que encuentre cierta esperanza en el amor.

Entonces, afirmamos que, en este personaje construido poéticamente, "ladrillo con ladrillo en un diseño mágico" ${ }^{12}$, se re-crea la subjetividad de cualquier obrero que vive, trabaja, ama y no deja de luchar teniendo como perspectiva su propia conciencia de clase. Y en relación a esto, coincidimos con Rafael Baldam principalmente en dos aspectos: en primer lugar, respecto de que el compositor de música popular tiende a dar voz al pueblo, hablando de sus "placeres, angustias, necesidades y su cotidiano" (2015: 24); en segundo lugar, respecto de que en las músicas populares hay un modo

\footnotetext{
${ }^{12}$ Séptimo verso de la canción "Construção".
} 
particular de "leer la realidad", donde emerge el compositor como un "portavoz de un tiempo o de una sociedad", que canaliza la voz a las clases oprimidas y re-crea la sociedad a partir de la perspectiva de las clases subalternas (2015: 5).

Sin embargo, consideramos que la operación que realiza la canción en su entramado sociocultural no es sólo de una función especular, sino de construcción de mundo, es decir, tiene carácter performativo. En torno a esto, Carolina Gomes plantea que debe tenerse en cuenta la relevancia del medio de difusión del discurso que, en el caso de la canción -difundida por radio o por discos, reinterpretada y tocada en vivo- goza de una alta reproductibilidad. Esto posibilita que el discurso poético construido por el compositor (al mismo tiempo que interpreta una realidad y un contexto) tenga carácter performativo y construya realidad. Al respecto, la autora enfatiza que "del mismo modo que la reproductibilidad de proposiciones puede reforzar una identidad hegemónica, la interrupción y el cuestionamiento de estas puede causar la interrupción de esas identidades y la creación de otras, nuevas y renovadas" (Gomes, 2009: 204). De este carácter performativo y reproductible se desprende lo efectivo del proceso de identificación que el discurso puede poner en marcha en aquellos que están marginados del poder. Al respecto, João Kogawa plantea que, en Buarque se puede observar, justamente, una marca de discurso con relación a la cuestión de los sujetos excluidos. Para el autor, "mediante un proceso de identificación, el discurso puede causar en los ciudadanos 'reales' un sentimiento de inquietud", pues el género canción tendría "el poder de despertar en los ciudadanos una conciencia crítica y una sensación de revuelta". En el caso de "Construção", por ejemplo, el sujeto que canta representa, para Kogawa, una clase de sujetos "reales" que componen la sociedad brasileña, y a partir de esto "entendemos que el sujeto de la canción pasa a ser un otro, con el cual los sujetos brasileños excluidos se pueden identificar y re-pensar su situación social" (2004: 9).

Tomando en cuenta, asimismo, que la construcción poética de esta subjetividad se desarrolla en un marco de censura y opresión política, es importante mencionar el concepto de "identidad subterránea" que Gomes desarrolla a partir del trabajo de Michael Pollak, entendiendo ésta como una identidad generada en forma paralela a la oficial. Esta identidad subterránea se manifiesta como una manera de mantener y transmitir una identidad colectiva en contextos de imposición de identidades hegemónicas oficializadas por las instituciones, y su forma de transmisión -como memoria- normalmente se da por medio de lazos entre amigos y familiares, y generalmente de forma oral. En relación al caso brasileño, para la autora, esta identidad subterránea es en su mayor parte registrada y transmitida mediante expresiones artísticas, "teniendo como una de las principales formas de registro y transmisión -en la época de la dictadura militar-aquellas realizadas dentro del sello de la denominada Música Popular Brasileira" (Gomes, 2009: 203). 


\section{Construcción poética del trabajador en el LP Construção}

En concordancia con lo afirmado, planteamos que en el LP de Buarque se teje la trama de vida de un trabajador construido poéticamente y que la unidad estructural del relato está dada por la canción que da nombre a la obra. Por tal motivo, proponemos un recorrido un poco más profundo de "Construção" que del resto de las canciones ${ }^{13}$. En segunda instancia, ofrecemos un análisis de "Deus Ihe Pague", debido a que esta canción funciona como coda de la anterior y comparte con ella una relación estrecha en el modo de protesta ante la injusticia. En tercera instancia, abordamos "Cotidiano", que expresa la trama de vida del trabajador atrapado en la rutina y la alienación. Tanto en esta canción como en las siguientes que analizamos, es decir, "Desalento" y "Valsinha", el amor aparece como fuerza desestructuradora y lugar de esperanza para romper con las injusticias que sufre la clase popular, siendo "Acalanto" su antítesis. Por último, vemos que "Minha História" se presenta como una especie de biografía de la alteridad, una biografía oculta(da) casi como se ocultan los males y la opresión.

\section{1. "Construção"}

Esta canción, en tanto cimiento sobre el que se levanta el encofrado, se apoyan los ladrillos y se coloca el techo, es la estructura de todo el disco. El personaje sin nombre que nace y vive dentro del disco muere injustamente en la obra (el paralelismo entre la obra de albañilería y la obra de arte es notable, puesto que el artista se coloca en el lugar del trabajador y viceversa). Ante la muerte, no queda sino el reclamo que surge y se repite en el disco de manera sorpresiva, como una manifestación que irrumpe en la plaza pública, lo que puede notarse en la coda que anticipa -o es anticipada por"Deus Ihe pague". Esa muerte injusta del personaje anónimo que representa la muerte de cualquier trabajador, no puede expresarse sino de manera disruptiva y subversiva. Por lo tanto, la mismísima estructura del poema transgrede la norma estilística impuesta por la lírica y la poesía clásica. Sin embargo, como hemos señalado con anterioridad, dentro de una poética existen decisiones por parte del autor y se dispone de ciertas normas. Las decisiones del poeta son decisiones emocionales, que funcionan como catalizadoras de las vivencias diarias, de habitar el mundo y "tener los pies puestos en la tierra" como lo manifiesta Buarque en una entrevista sobre "Construção", en 1973:

No pasaba de ser una experiencia formal, un juego de ladrillos. No tenía nada que ver con el problema de los operarios -siempre evidente, además, cuando uno mira por la ventana. [...] En el momento en que compongo no hay intención -sólo emoción. En

\footnotetext{
${ }^{13}$ Tomamos como referencia para este artículo el orden cronológico de las canciones como se presenta en el LP de 1971: Lado 1. "Deus Ihe pague", "Cotidiano", "Desalento", "Construção"; Lado 2. "Cordão", "Olha Maria", "Valsinha", "Samba de Orly", "Minha história", "Acalanto".
} 
Construcción la emoción estaba en el juego de palabras (todas esdrújulas). Ahora, si tú pones a un ser humano dentro de un juego de palabras, como si fuese... un ladrillo acabas tocando la emoción de las personas. [...] Hay diferencia entre hacer una cosa con intención o -en mi caso- sin preocupación del significado. Si yo viviese en una torre de marfil, aislado, talvez saldría un juego de palabras con algo etéreo en el medio, la Patagonia, talvez, que no tiene que ver con nada. En resumen, no pondría en la letra a un ser humano. Pero no vivo aislado. Me gusta ir a la taberna, jugar billar, oír las conversaciones en la calle, ir al fútbol. Todo entra en la cabeza en tumulto y sale en silencio. Entonces es resultado de una vivencia no solitaria que contrapesa el juego mental y es garantía de tener los pies bien puestos en la tierra (Patarra, 1973).

Respecto de las normas establecidas por quien poetiza, podemos reconocer que en "Construção" prima una "anomia planificada". Este concepto que acuñamos expresa que la aparente ruptura de normas es la norma por antonomasia dentro de la canción, y no es una anomia espontánea, sino que es consciente y planificada, del mismo modo que lo es un golpe de estado o una revolución. Esto puede notarse en la cadencia de las palabras en cada verso, que produce un efecto de extrañación a lo largo de todo el poema. Frente a lo usual y lo común (en general) de la rima entre sílabas o palabras de acentuación grave o aguda, Buarque introduce una rima "extraña" (tan extraña y sorpresiva como debería ser la muerte de un obrero), hecha a partir de la sonoridad de la acentuación esdrújula. Esta licencia poética consigue que la rima no se produzca con la sílaba final de la palabra, sino con la primera. Y ésta es la primera disrupción que subvierte el sistema poético y, acaso, el sistema político: el trabajo de un obrero debería estar en primera línea de atención, tal como sentencia la rima:

Amou daquela vez como se fosse a última

Beijou sua mulher como se fosse a última

E cada filho seu como se fosse o único

E atravessou a rua com seu passo tímido

Subiu a construção como se fosse máquina

Ergueu no patamar quatro paredes sólidas

Tijolo com tijolo num desenho mágico ${ }^{14}$
Amó aquella vez como si fuese última Besó a su mujer como si fuese última Y a cada hijo suyo cual si fuese el único Y atravesó la calle con su paso tímido Subió a la construcción como si fuese máquina Alzó en el balcón cuatro paredes sólidas Ladrillo con ladrillo en un diseño mágico ${ }^{15}$

Por otro lado, el sistema de palabras esdrújulas es mucho más reducido que el de las palabras graves y agudas, de manera que crear a partir de ellas es mucho más complejo que por medio de palabras acentuadas en la última y en la penúltima sílaba. Entonces, al tratarse de un sistema reducido de palabras, el poeta repite vocablos y se vale dos veces del mismo recurso (tal como puede notarse,

\footnotetext{
14 Énfasis nuestros.

${ }^{15}$ A menos que se indique lo contrario, las traducciones al español de Construçao son de Daniel Viglietti en el LP Chico Buarque en español (Buarque, 1982) y han sido recuperadas del sitio web oficial de Chico Buarque (Homem, SF).
} 
por ejemplo, en los primeros dos versos citados), lo que decanta en la exaltación del recurso de la repetición y de la aliteración. En definitiva, la carencia de palabras esdrújulas dentro de nuestro sistema lingüístico lleva al poeta a "repetirse" y se vuelve equivalente a la carencia material del trabajador, que se sustenta con poco y repite constantemente la misma rutina. Además de la utilización repetitiva de "última" en los dos primeros versos, la misma palabra reaparece unos versos más abajo, pero esta vez en masculino: "Amou daquela vez como se fosse o último".

El uso constante del "como si" (recurso poético de la prosopopeya), sumado a los verbos en subjuntivo -modo de la irrealidad o de la posibilidad-tales como "fosse" (fuese) a lo largo del poema, produce ese efecto de distancia material de aquello que no se tiene: la realidad del trabajador que no puede alcanzar su sustento material ni su reconocimiento en tanto pieza fundamental dentro de un sistema que lo oprime. Entonces, descansa a la hora del almuerzo unos minutos y hace durar ese instante "como si" fuese sábado, almuerza "como si" su feijão fuese un banquete de príncipe y bebe abundantemente, cual náufrago. Y ya solamente a partir de esos versos se puede notar cómo sitúa al trabajador en diferentes roles sociales que no ocupó (como denuncia por la ausencia de movilidad social) ni podrá soñar en ocupar. Por tal motivo, el primer verso sentencia que "sus ojos siguen cubiertos de cemento y lágrimas", su trabajo-tortura ${ }^{16}$ lo invade mientras sueña y no termina hasta producirle la muerte:

Seus olhos embotados de cimento e lágrima

Sentou pra descansar como se fosse sábado

Comeu feijão com arroz como

se fosse um príncipe

Bebeu e soluçou como se fosse um náufrago sus ojos embotados de cemento y lágrimas sentóse a descansar como si fuese sábado comió su pan con queso cual si fuese un príncipe bebió y sollozó como si fuese un náufrago

Frente al "como sí" de la ficción, que sugiere una posibilidad imaginaria, aparece el peso del modo indicativo, modo de la realidad, con verbos en pretérito -tiempo de las acciones sucedidas antes del presente y, por tanto, inalterables-tales como "acabou" (acabó), "morreu" (murió), "agonizou" (agonizó) -todos con matices de sufrimiento y fin. Asimismo, son notables las formas participiales tales como "feito" (hecho), que dan cuenta de un hecho que tiene correlato con la realidad interna (o externa) del poema. El hombre cayó del andamio - una posible lectura nos lleva a pensar que cayó con motivo de la embriaguez, en tanto espacio de

\footnotetext{
${ }^{16}$ Etimológicamente, el término "trabajo" se vincula con la tortura del "tripalium”, herramienta similar a un cepo con tres puntas que servía para sujetar caballos y herrarlos. Pero esa misma herramienta también se utilizó como medio de tortura para castigar esclavos. Por tanto, el verbo "trabajar" se vincula con "tripaliare" que puede traducirse como "torturar", "atormentar" o "causar dolor".
} 
evasión de la realidad asediante- y murió, no hay posibilidad imaginaria de salir del espacio de la muerte:

E se acabou no chão feito um pacote tímido Agonizou no meio do passeio náufrago Morreu na contramão atrapalhando o público [...]

Ese acabou no chão feito um pacote bêbado Morreu na contra-mão atrapalhando o sábado
Y terminó en el suelo como un bulto tímido Agonizó en el medio del paseo náufrago Murió a contramano entorpeciendo el público

Y terminó en el suelo como un bulto alcohólico Murió a contramano entorpeciendo el sábado

A lo largo del disco, el personaje trabajador pierde por momentos la voz, mientras pareciera ser "hablado" (Bourdieu, 1985) a partir del discurso hegemónico de la prensa al interior del mismo relato. Esta canción, escrita en tercera persona, alterna versos que hacen pensar en el discurso que podría emitir la prensa (como en el verso: "Morreu na contra-mão atrapalhando o tráfego") frente a otro tipo de versos que guardan relación con la vida íntima del protagonista muerto, "hablado" a partir del discurso de sus familiares y amigos ("Amou daquela vez como se fosse a última"). Y el mismo Buarque también ejerce una voz de poder (una voz poética que va a contrapelo del discurso de la prensa), voz contrahegemónica que narra las peripecias del trabajador a lo largo de su vida y su desenlace fatal.

\section{2. "Deus lhe pague"}

Ninguna canción desatiende la necesidad de desnaturalizar los roles sociales impuestos por la clase opresora sobre los trabajadores. Un claro ejemplo de ello es "Deus the pague", canción que abre el disco. La tónica general del poema está cargada de ironía, tópico preferido de la literatura para producir efecto de crítica social y moral:

Por esse pão pra comer, por esse chão pradormir

A certidão pra nascer e a concessão pra sorrir

Por me deixar respirar, por me deixar existir

Deus Ihe pague
Por ese pan de comer y el suelo para dormir,

Registro para nacer, permiso para reír, Por dejarme respirar y por dejarme existir Dios le pague

Este poema aparece y desaparece en un ciclo constante, como satélite de "Construção"17, es decir, tiene una aparición en tanto coda (absolutamente dependiente) de dicha canción y tiene asimismo una versión independiente, como canción autónoma. Esta disrupción propia de la poesía (vale pensar que un libro de poemas no se lee necesariamente por la página inicial, sino que admite saltos

\footnotetext{
${ }^{17}$ Siguiendo la misma secuencia de apariciones y desapariciones de "Deus le Pague", optamos por hacer un análisis repartido (al igual que en el disco) en dos partes independientes que insisten en el mismo lema de búsqueda de justicia. Por tal motivo, el análisis que iniciamos en este punto se retomará en las páginas siguientes.
} 
de página y posibilita la lectura de atrás para adelante, por ejemplo) que redunda y repite esta especie de estribillo no tiene sino otra función que la insistencia como medio de denuncia urgente. En este sentido, "Deus Ihe pague" funciona como la rememoración que evocan, por ejemplo, los estribillos en la canción de protesta. Entonces, podemos arriesgar que la canción constituye un estribillo extenso que expresa versos de rebelión absoluta y de denuncia necesaria en un tono particular y con recursos diferentes a los del resto de las canciones que componen el álbum. Así, dentro de la misma lógica interna del poema-estribillo, aparece cada tres versos un estribillo-del-estribillo que murmura constantemente el título de la canción. La expresión "Deus Ihe pague", puede referirse a las palabras mencionadas por quien recibe una limosna a modo de agradecimiento y, al mismo tiempo, puede vincularse con la idea de que todo mal sucedido -por ejemplo, la muerte del personaje que cae del andamio en "Construção"- no tiene otro tipo de compensación que la divina.

Asimismo, la inclusión de una frase hecha cristalizada (y, por ende, naturalizada) del habla cotidiana en el poema insiste en la necesidad de cuestionar el sentido común. La frase hecha y los refranes son frases de sentido común (las personas las repiten casi sin pensarlas) que, al mismo tiempo, desafían ese sentido. El poeta retoma esa frase, la pone en cuestión y lo hace a través de la ironía. Ni Dios ni nadie va a pagar nada. Y el "pago" por la muerte no tiene precio. Por lo tanto, solo hay un castigo posible y ese castigo es la sentencia social. Sólo queda la posibilidad de agredir -por medio de la poesía- al sistema que ejerce violencia simbólica sobre el trabajador, que lo obliga a callar "com a boca de feijão" y a no gritar que el pago por la muerte no se sustenta en un intercambio monetario y que la vida no puede estar sujeta a las normas estrictas del sistema laboral. En este aspecto y en concordancia con el trabajo de Bourdieu, existe un mercado lingüístico conformado por "discursos estilísticamente caracterizados [...] que se colocan a su vez del lado de la producción en la medida en que cada receptor contribuye a producir el mensaje que recibe introduciendo en él todo lo que constituye su experiencia singular y colectiva" (1985: 13). En este intercambio, la polisemia del lenguaje religioso produce un efecto ideológico de unificación de los contrarios o de negación de las divisiones sociales. Y, como la unificación resulta imposible en vida y no existe una negación de las divisiones sociales en el contexto del trabajo -dentro del sistema capitalista-, el único espacio de redención y de igualación social es la muerte. Por tal motivo, esa sentencia que reza el estribillo no es otra cosa que la búsqueda constante de justicia de quien trabaja "por ese pan para comer y por ese suelo para dormir" y vive en un sistema de constantes prohibiciones que lo mantienen muerto en vida, ya que requiere, incluso, "registro para nacer y permiso para reír". Entonces, el trabajador de "Construção" muere doblemente. La primera vez, lo hace en la rutina asediante del trabajo, que lo separa del placer porque el amor se hace de prisa cuando el ritmo de vida lo impone el trabajo: "o 
amor malfeito depressa, fazer a barba e partir". La segunda vez, muere cuando cae del andamio. El doble discurso de la muerte está estribado primero en los protagonistas que la padecen de cerca y, después, en el discurso de la prensa que nos distrae y minimiza el acontecimiento: "Um crime pra comentar e um samba pra distrair". Por tal motivo, se puede pensar que el título de la canción, en tanto estrategia para la memoria, sentencia el tópico clásico de la fugacidad de la vida, una versión del clásico memento mori que insiste en que recordemos que vamos a morir y que la juventud se termina pronto. El memento mori de la canción de Buarque pone el énfasis en la fugacidad del tiempo del obrero, incrustado en los engranajes del trabajo que acelera las vidas y las acorta hasta su fin. Y no hay "dios que pague" por ese crimen simbólico.

\section{3. "Cotidiano"}

El personaje de Construção, como todo trabajador, tiene una rutina laboral sembrada de pequeños oasis (no por ello menos relevantes). El pequeño oasis aparece, en general, como hemos señalado al inicio de este apartado, ligado al amor que salva de la rutina frenética al obrero y cumple la tarea de desnaturalizar lo natural, tal como el beso "con la boca de menta" que recibe el trabajador por parte de su amada, frente a la función usual de la boca que se utiliza para comer (razón del sacrificio para todo trabajador). Esto se vuelve visible en las siguientes estrofas de "Cotidiano", canción que, desde su título, ya alude de la repetición el recurso poético ingresa en la vida del trabajador (o a la inversa)-, con la sentencia que encarama cada inicio de la estrofa, "cada día". Por otro lado, a la rutina avasallante se le superpone el pensamiento del trabajador que piensa "en poder parar" pero silencia su propia voz interior para que no se convierta en palabra y, ante la resignación, se calla, llenándose la boca de feijão. En estos sencillos pero contundentes versos, el poeta da cuenta del lugar asignado socialmente al trabajador, que parece no tener la tarea de pensar, sino de trabajar por su propio sustento:

Todo dia ela faz tudo sempre igual me sacode às seis horas da manhã me sorri um sorriso pontual e me beija com a boca de hortelã. [...]

Todo dia eu só penso em poder parar meio-dia eu só penso em dizer não depois penso na vida prá levar e me calo com a boca de feijão
Cada día ella siempre hace todo igual me despierta a las seis antes que el sol me sonríe con sonrisa puntual y me besa con boca de mentol

Todo el día yo pienso en poder parar al mediodía pienso en decir no luego pienso en la vida y continuar y me callo con boca de arroz 


\section{4. "Desalento"}

El personaje real-ficticio de Buarque no puede ignorar que su realidad es adversa, de modo que la asunción de la conciencia de clase lo conduce a proferir poemas (y con ellos, confesiones) de poca esperanza y tristes, tales como "Desalento". Esto se debe a que existe un correlato entre la existencia material de los personajes y sus propias manifestaciones. En este punto, el intercambio lingüístico se encuentra ligado al intercambio económico. El personaje que atraviesa todo el disco, inscripto en una realidad de pobreza, expresa en sus palabras una evidente conciencia de clase. Este reconocimiento de las realidades que lo circundan contribuye a crear un realismo estribado en el lenguaje (Bourdieu, 1985). Y esto no sucede solamente para despertar la empatía de quien escucha la canción, esa especie de hermandad de huérfanos que siempre produce el discurso del desamor. En "Desalento" hay algo más: existe una pérdida de amor sustentada en el discurso sobre la otredad respecto de las clases burguesas. Esa otredad en la que vive nuestro personaje está signada por el discurso de la clase dominante y él constantemente busca el "medio" de una tercera persona para "dar explicaciones", casi como si tuviera que usar otro canal fonador para expresar su propia voz:

$\begin{array}{ll}\text { Sim, vai e diz } & \text { Si, anda y dile } \\ \text { Diz assim } & \text { Dile así } \\ \text { Que eu rodei } & \text { Que rodé } \\ \text { Que eu bebi } & \text { Que bebí } \\ \text { Que eu caí } & \text { Que caí } \\ \text { Que eu não sei } & \text { Que no sé } \\ \text { Que eu só sei } & \text { Que sólo sé } \\ \text { Que cansei, enfim } & \text { Que me cansé, en fin } \\ \text { Dos meus desencontros } & \text { De mis desencuentros } \\ \text { Corre e diz a ela } & \text { Corre y dile a ella } \\ \text { Que eu entrego os pontos } & \text { Que me doy por vencido18 }\end{array}$

\section{5. "Valsinha"}

Casi todos los personajes fictivos del disco de Buarque encuentran en el amor familiar y de pareja un espacio de pausa ante la temible alienación. Esto resulta evidente en "Valsinha", canción que cuenta cómo -después de un día común y corriente de trabajo- el operario llega a casa mirando y hablando de manera distinta, sin su acostumbrado cansancio, sin maldecir la vida como suele hacer. Y ese cambio que lo saca de la repetición sistemática del trabajo, cambio extraño en

\footnotetext{
18 Traducción nuestra.
} 
apariencia, es posible desde la perspectiva de dos enamorados que bailan felices y para quienes ellos solos constituyen el hito histórico para la paz del mundo:

E ali dançaram tanta dança que a vizinhança toda despertou

E foi tanta felicidade que toda a cidade se iluminou

E foram tantos beijos loucos

Tantos gritos roucos como não se ouvia mais Que o mundo compreendeu

E o dia amanheceu

Em paz
Y allí bailaron tanta danza

que toda la vecindad se despertó

$Y$ fue tanta felicidad que toda la ciudad se iluminó

Y fueron tantos besos locos

\section{6. "Acalanto (acalanto para Helena)"}

En portugués, un acalanto es un arrullo, una canción de cuna. Buarque compone esta canción para su hija Helena, que acababa de nacer en diciembre de 1970, y cumple la función de cierre del disco. Allí donde "Valsinha" representa la esperanza, "Acalanto" funciona como contrapunto, que conjuga el amor paterno con la desesperanza de alguien que ve nacer a su hija en contexto de dictadura. Así, aun cuando el hablante expresa la posibilidad de una salida -a una "aurora más serena"-, al mismo tiempo abre y cierra la composición con la dura sentencia "no vale la pena despertar". La emoción preponderante que el "yo" expresa -que entendemos como emoción del padre-trabajador hacia su hija en un entorno de represión política- se manifiesta ya en la primera palabra del poema. Se utiliza la estrategia de sinéresis o contracción entre las palabras "Dorme" y "Minha" ("duerme" y "mi" [fem.]), donde la sílaba final de dorme es igualada con la sílaba inicial de minha. Por una parte, esto conduce a la fusión (quizá siempre implícita) entre "duerme" y "mi" y, por otra parte, opera una incisión sobre la palabra "dorme" que la transfigura, convirtiéndola en "dor" (dolor). Es posible pensar, así, que estas palabras son "rotas" por el contexto de censura, y conducen entonces a un lenguaje reinventado, es decir, a una búsqueda constante de expresión que no se limita al uso habitual de la palabra. El guiño implícito en la sinéresis es el de ruptura y unión, gestos simultáneos que subyacen a una sola operación poética, como si manifestaran estrategias -poéticas y políticas- ante la censura y la opresión. El "dor" queda contenido -implicado-entonces, en el "dorme" expresado por el arrullo.

Dor(me) minha pequena

Não vale a pena despertar

Eu vou sair por aí afora

Atrás da aurora mais serena
Duerme mi pequeña

No vale la pena despertar

Voy a salir por ahí, afuera

Tras la aurora más serena20

\footnotetext{
19 Traducción nuestra.

${ }^{20}$ Traducción nuestra.
} 


\section{7. “Minha história"}

Nuestro personaje de ficción tiene incluso una biografía, que bien podría ser la historia de vida de cualquier trabajador de la clase popular. "Minha História" es la única canción del disco de la cual Buarque no es autor. La obra es de Lucio Dalla y Paola Pallotinno (1971) y lleva por título "4/3/1943" (fecha de nacimiento de Dalla), aunque, tal como las canciones de Buarque, esta canción -que originalmente llevaba por título Gesù Bambino ${ }^{21}$ - sufrió en Italia los embates de la censura por ser considerada irrespetuosa. "Minha História" es una ficción biográfica y Buarque la ubica, como si intentara presentar tardíamente a su personaje -quizá de manera póstuma- casi al final del LP.

Quando enfim eu nasci, minha mãe embrulhou-me num manto

Me vestiu como se eu fosse assim uma espécie de santo

Mas por não se lembrar de acalantos, a pobre mulher

Me ninava cantando cantigas de cabaré.
Cuando finalmente nací, mi madre me envolvió en una manta

Me vistió como si fuese algo así como una especie de santo

Pero al no recordar canciones de cuna, la pobre mujer Me arrullaba cantando canciones de cabaret.

Existe, entonces, un mundo (¿imaginario?) poético de Buarque, que atiende a la vida de los personajes de la clase popular brasileña (Moraes, 2004), a la rutina de los hombres y mujeres que trabajan y que tienen historias de amor, de desamor y de muerte. La coexistencia dentro de Construção es más bien una especie de convivencia, con saltos y disrupciones que invaden no sólo la lógica interna de los poemas, sino también el mismo disco-poemario de Buarque. Si el principio fundamental de la rutina del trabajador es la repetición, el automatismo y lo recurrente, las composiciones de Buarque justamente proponen un punto de quiebre que no desatiende la presencia de la alienación y la resignifica. Buarque exhibe que, incluso en el trabajo más duro y alienante, existen espacios de creación; que, frente al negocio (etimológicamente entendido como la negación del ocio), debe haber ocio, breves oasis de libertad para planear la lucha. En este marco, proponemos que la creación de esta poética (mundo paralelo suscitador de realidades) irrumpe bajo la presión de un mundo hostil que no puede y no debe perder la música y, con ella, la alegría, la esperanza y la decisión de lucha.

Cada pieza contenida en el disco parece aportar un punto de vista singular a una idea general más amplia, que es el disco como unidad, siendo la canción que le

21 "Niñito Jesús" 
da nombre al disco, "Construção", el núcleo de este discurso. Así, desde esta canción central se puede navegar hacia las demás en múltiples órdenes posibles. El primer eslabón se establece naturalmente hacia "Deus Ihe Pague", tanto por las ideas musicales expuestas como por la temática, constituyéndose en canciones hermanas, casi misteriosamente unidas, al punto que la primera culmina con una cita a la segunda; una enunciación que, en el orden original del LP -que las presenta invertidas-, funciona como un racconto elaborado que lleva al oyente a percibir una circularidad que podría no tener fin, planteando perceptualmente la necesidad de que "Construção" se reinicie una y otra vez. Esta relación íntima entre ambas músicas se da por la confluencia entre dos estructuras armónicas simples sustentadas en una misma tonalidad, mi menor, que funciona como eje tonal común, y, asimismo, por la persistencia rítmica del patrón de corcheas que, como maquinaria de reloj, insiste en mantenerse presente marcando simultáneamente el tempo musical y el tiempo cronológico en su irreversibilidad.

Allí donde "Construção" funciona como narración -casi periodística- de la caída desde las alturas a la muerte, dejando entrever la distancia propia de una crónica, "Deus lhe Pague" opera como un reclamo irónico de la condición de precariedad del mismo obrero: "Pelos andaimes pingentes que a gente tem que cair". Se establece, entonces, una relación de observación doble sobre un mismo asunto: primero, se narra la historia que le ocurre a un otro; luego, el sujeto que enuncia, el sujeto que canta, es protagonista directo del reclamo, construyendo un nosotros que expresa su propia emocionalidad. Se constituye entonces una especie de lamento que provoca la aparición plena del coro -el colectivo-, el que paulatinamente, en el transcurso de "Construção", se fue sumando a la enunciación en un proceso de crecimiento constante, pasando de hacer lectura distante de la crónica a constituirse en manifestación de la propia subjetividad colectiva.

El proceso de crecimiento -el aumento paulatino de la masa orquestal ${ }^{22}$ - se entrelaza, entonces, con el paso narrativo de un "él", a un "yo" ("por dejarme respirar, por dejarme existir"), luego a un "ellos" ("la gente") y, finalmente, a un "nosotros" ("y por el grito demente que nos ayuda a huir") que encarna al colectivo que enuncia y denuncia en un mismo acto de habla. Hay, sin duda, en este procedimiento de elaboración del sonido y el texto en profunda relación, rasgos que acercan a "Construção" y "Deus Ihe Pague" a géneros como la cantata, el oratorio y la ópera, haciendo pensar en las relaciones tradicionales entre un aria o recitativo, canto solista que toma el lugar del sujeto que habla de otro y de sí, y un coro, que podría representar a la historia y la palabra de la comunidad.

\footnotetext{
${ }^{22}$ La orquestación del disco es realizada por el maestro Rogério Duprat.
} 
Desde el plano del análisis literario, este desdoblamiento de la primera persona del singular a la primera del plural, la sumatoria de voces hermanadas al final de "Deus the pague" y la interacción de diversos discursos a lo largo de "Construção" (anteriormente hemos hecho referencia a los versos intercalados con lo que podrían ser voces de la emotividad y voces de los medios masivos de la comunicación) nos remite a la novedad que suscitó el surgimiento de la novela moderna. Esta última, según Mijaíl Bajtín (1989) propulsó la novedad de la polifonía, es decir, la interacción de varias voces que permitían vislumbrar la coexistencia de registros y puntos de vista diversos en un mismo cuerpo de texto. Por lo tanto, la polifonía se vuelve un discurso de predilección para la inclusión de la voz de las masas y su intervención en un relato de ficción que -siguiendo con la díada de lo fictivo y lo real-, bien podría cuajar con la insistencia de la inclusión de la voz de del sujeto trabajador entre las voces opresoras del discurso dominante.

\section{Cadencia}

En resumen, el trabajador cayó, pero no calló. La rutina lo imbuye en una espiral sin fin, en una ruina espiral de difícil retorno donde el pulso-ritmo de la vida se acelera y no da casi espacio al desarrollo de la vida fuera de la tortura que implica el trabajo. La cuerda de vida que sostiene al obrero lo hace pender de un hilo y, de pronto, gran parte de su existencia se limita a la búsqueda del sustento material para mantenerse en pie. El trabajador puede caer, pero no callar; su expresión más íntima y revolucionaria es la canción. En este punto, la poesía, en tanto instancia creadora de universos que sobrepasan la díada entre lo ficticio y lo real, y la música, medio que no solo sirve de canal de difusión de la palabra, sino que acompaña al discurso del trabajador estribado en la necesidad por incluir los sonidos y las voces de las clases populares, se funden $-y$ se confunden, si retomamos el recurso de "driblar" que señala Marcadet (2005)en una masa indivisible que en mucho se parece a la mezcla de cal, agua y arena. Esa mezcla que no fragua contribuye a que la vida del obrero penda de un hilo, pues éste cae con "su paso alcohólico" en "Construção" y ya no puede erguir "cuatro paredes sólidas" sino "flácidas". Todo este universo creado a partir de "Construção" tiene un correlato a lo largo del disco. El trabajador, en efecto, nace, crece, trabaja, vive, sueña, se enfurece, ama y muere en las "cuatro paredes" de la obra de Buarque.

La irrupción de la MPB en los años 1960 fue una piedra angular que puso énfasis en el valor del reclamo, la denuncia y la defensa de la clase popular brasileña. Asimismo, desde sus orígenes hasta la creación que estamos analizando, tuvo una evolución que decantó en la exaltación de la lucha, los mensajes revolucionarios y la necesidad de combatir el sistema capitalista que oprime a los sectores menos acomodados de Brasil, sin desatender por ello la urgencia por 
desentrañar la violencia, la persecución y la censura en el contexto de dictadura. En este marco, la proliferación de recursos que contribuyen a la exaltación de la voz popular (tales como la polifonía y el traspaso de un canto solista recitativo a la voz colectiva del coro) se hace manifiesta en la música y en la palabra (esto se vuelve evidente en "Deus Ihe pague" y "Construção"). Esta voz poética que se encuentra constantemente bajo la amenaza del silencio coexiste $y$, en ocasiones, lucha contra el discurso hegemónico de las clases dominantes encaramado en la prensa.

En cuanto las estrategias literarias utilizadas, cabe señalar que Buarque desestabiliza el sistema poético clásico y que en ese guiño poético reside también su crítica poética. La rima esdrújula de "Construção" participa en esa anomia planificada que consiste en volver extraño lo habitual para poner énfasis en la situación injustamente naturalizada del trabajador explotado. Una función similar cumple la inclusión de frases hechas ("deus le paghe") como estrategia de crítica al menos común de los sentidos, es decir, el sentido común. En definitiva, a lo largo del ensayo hemos dado cuenta de la presencia de numerosas estrategias musicales y literarias que re-crean poéticamente la vida y el sentir de un trabajador de la clase popular brasileña. La ilusión de parar el reloj que da cuerda a la rutina y, con ella, al trabajo -en tanto tortura necesaria y $\sin$ fin-y el remordimiento de no poder hablar en ocasiones, no deja de lado la certeza de no tener más nada que ofrecer que constante lucha, la esperanza y la agonía. A modo de cierre, nos resulta importante incluir un poema que, si bien no hemos analizado, creemos que resume acaso las ideas que hemos querido exponer; nuestro personaje, cansado de trabajar y de perder (la lucha, la voz, la vida) le expresa estas ideas a su hermosa María, ante su abandono:

Vai, alegría
Que a vida, Maria
Não passa de um dia
Não vou te prender
Corre, Maria
Que a vida não espera
É uma primavera
Não podes perder
Anda, Maria
Pois eu só teria
A minha agonia
Pra te oferecer
Anda, alegría
Que la vida, María
No pasa de un día
No te retendré
Corre, María
Que la vida no espera
Y una primavera
No puedes perder
Anda, María
Pues yo sólo tendría
La agonía mía
Para ofrecerte 


\section{Referencias}

\section{Artículos}

Antequera, José (2008). Oralidad y difusión poética en la Nueva Canción Latinoamericana. Voz y Escritura. Revista de Estudios Literarios, (16). 91-111.

Bajtin, Mijail (1989). Teoría y estética de la novela. Madrid: Taurus.

Baldam, Rafael; Viana Leonelli, Gisela (2015). Cidade Cantada: A Representação dos Conflitos Urbanos pela Análise Musical. Anais XVI ENANPUR Espaço, Planejamento e Insurgências: Alternativas Contemporâneas para o Desenvolvimento Urbano e Regional. Belo Horizonte: Anpur/UFMG. Recuperado el 27 de diciembre de 2015 de http://xvienanpur.com.br/anais/?wpfb_dl=470.

Bourdieu, Pierre (1985). ¿Qué significa hablar? Economía de los Intercambios Lingüísticos. Madrid: Akal.

Carmo Jr., José Roberto do (2007). Melodia e Prosódia: um modelo para a interface música fala com base no estudo comparado do aparelho fonador e dos instrumentos reais e virtuais. São Paulo: FFLCH/ USP. Recuperado el 25 de diciembre de 2015 de http://www.teses.usp.br/teses/disponiveis/8/8139/tde-12112007-141109/ptbr.php.

Carvalho, Stephanie; Rocha, Luana Paula; Silva, Jéssica Natalia; Toso, Sthefany (2015). A censura às músicas de Chico Buarque na ditadura (1964-1985). Observatório da Imprensa, (849). Recuperado el 27 de diciembre de 2015 de http://observatoriodaimprensa.com.br/diretorio-academico/a-censura-as-musicas-de-chico-buarque-na-ditadura-1964-1985/.

Dias Cavalcanti, Luciano (2011). Música popular e poesia no Brasil: um breve percurso histórico. Darandina Revisteletrônica, 4(1). Recuperado el 27 de diciembre de 2015 de http://www.ufjf.br/darandina/anteriores/v4n1/arr/.

(2012). Música Popular Brasileira, Política e Utopia em Chico Buarque. Recorte, 9(2). Recuperado el 27 de diciembre de 2015 de http://revistas.unincor.br/index.php/recorte/article/view/637.

Éribon, Didier (1982), Sur Ce que parler veut dire. Pierre Bourdieu. Libération. 19 de octubre. 28. Recuperado el 28 de diciembre de 2015 de http://sociologiac.net/2008/01/17/entrevista-pierre-bourdieu-que-significa-hablar/.

Gomes Paulse, Carolina (2009). Cantando a resistência, construindo identidade: análise das canções de Chico Buarque. Anais III Semana de Pesquisa em Artes Art/Uerj. Rio de Janeiro: UERJ. 200-216. Recuperado el 27 de diciembre de 2015 de http://www.ppgartes.uerj.br/spa/spa3/anais/carolina_paulse_200_216.pdf.

Harshaw, Benjamin (1997) Ficcionalidad y campos de referencia. En: Garrido, Antonio, comp. Teorías de la ficción literaria. Madrid: Arco. 123-157. 
Iser, W. (1997). La ficcionalización: dimensión antropológica de las ficciones literarias. En: Garrido, Antonio, comp. Teorías de la ficción literaria. Madrid: Arco. 43-65.

Kogawa, João Marcos Mateus (2004). O discurso-arte de Chico Buarque: poder sobre o sujeito brasileiro. Revista Urutágua - acadêmica multidisciplinar, (7). Recuperado el 27 de diciembre de 2015 de http://www.urutagua.uem.br/007/07kogawa.pdf.

Marcadet, Christian (2005). "Driblar la Censura" o cómo el proyecto creador de Chico Buarque redefinió la recepción de las canciones en Brasil durante los años de dictadura. Anais VI Concreso IASPM-AL. Buenos Aires: IASPM-AL. Recuperado el 28 de diciembre de 2015 de http://www.iaspmal.net/anais/buenosaires2005/pdfs/.

Marchesse, Angelo; Fordarellas, Joaquín (1989). Diccionario de Retórica, Crítica y Terminología Literaria. Barcelona: Ariel.

Martínez, Leonardo (2011). Música y poesía, un dios compartido. En: Foguet, Hugo et al. La música de la poesía. Buenos Aires: Dock.

Moraes, Rodrigo (2004). O Alarido das Vidas Marginais na Obra de Chico Buarque. Psicologia Ciência e Profissao, 24(4). p.30-41. Recuperado el 05 de enero de 2016 de http://ref.scielo.org/wkvq7h.

Patarra, Judith (1973). Notas sobre Construção. Chico Buarque (sitio web). Recuperado el 27 de diciembre de 2015 de http://www.chicobuarque.com.br/letras/notas/n_construc.htm.

Paz, Octavio (1994) Sor Juana o las trampas de la fe. En: Cruz, Sor Juana Inés de la. Obra selecta. 11-39. Recuperado el 2 de enero de 2016 de http://www.biblioteca.org.ar/libros/211689.pdf.

Priore, Irina; Stover, Chris (2014). The Subversive Songs of Bossa Nova: Tom Jobim in the Era of Censorship. Analytical Approaches to World Music, 3(2). Recuperado el 05 de enero de 2016 de http://www.aawmjournal.com/articles/2014b/Priore_Stover_AAWM_Vol_3_2.html.

Salas, Horacio. (2011). Música/poesía, Poesía/música. En: Foguet, Hugo et al. La música de la poesía. Buenos Aires: Dock. 108-118.

Severiano, Jairo; Homem de Mello, Zuza (1997). Notas sobre Roda Viva. 85 anos de Música Brasileira, vol. 2. Sao Paulo: 34. Recuperado el 05 de enero de 2016 de http://www.chicobuarque.com.br/letras/notas/n_zuza_rodaviva.html.

Stevenson, Robert Louis (2014). The art of writing (e.book). Adelaide: The University of Adelaide. Recuperado el 24 de diciembre de 2015 de https://ebooks.adelaide.edu.au/s/stevenson/robert_louis/s848aw/complete.html.

Velasco, Fabiola (2007) La Nueva Canción Latinoamericana. Notas sobre su origen y definición. Presente y Pasado. Revista de Historia, 12(23). Venezuela: ULA. 139-153.

Werney, Alfredo (2009) Articulação entre melodia e prosódia na canção popular brasileira: uma análise de Retrato em branco e preto. Revista dEsEnrEdoS, 1(2). Recuperado el 2 de enero de 2016 de http://www.desenredos.com.br/arquivo_129.html. 
Cristian Galarce y Lucía Di Salvo. La construcción poética del trabajador en el disco Construção...

\section{Sitios web}

Homem, Wagner, ed. (SF). Chico Buarque (sitio web). Accesado el 2 de diciembre de 2015 en http://www.chicobuarque.com.br/.

IACJ, ed. (SF). Instituto Antonio Carlos Jobim (sitio web). Accesado el 2 de diciembre de 2015 en http://www.jobim.org/.

\section{Documentales}

Oliveira, Roberto de (2005). Chico Buarque - Vai Passar. EMI. Brasil. (2006). Chico Buarque - Roda Viva. EMI. Brasil.

Salles, Walter; Motta, Nelson (1989). Chico ou o País da Delicadeza Perdida. Videofilmes/FR3. Brasil/Francia.

\section{Discografía}

Buarque, Chico (1968). Chico Buarque de Hollanda Vol. 3. RGE. Brasil. (1971). Construção. Phonogram/Phillips. Brasil.

(1982). Chico Buarque en español. Polygram. Brasil (1993). Não Vai Passar Vol. 4. RGE. Brasil.

Jobim, Tom (1970). Stone Flower. CTI. EE.UU. 